\title{
Swimming depth and ocean currents affect transit costs in Steller sea lions Eumetopias jubatus
}

\author{
Allyson G. Hindle*, David A. S. Rosen, Andrew W. Trites \\ Marine Mammal Research Unit, Fisheries Centre, AERL, University of British Columbia, 2202 Main Mall, Vancouver, \\ British Columbia V6T 1Z4, Canada
}

\begin{abstract}
Transit costs associated with commuting between resting sites ashore and foraging areas at sea constitute an appreciable portion of foraging expenditures in pinnipeds. We examined transit swimming in 3 Steller sea lions Eumetopias jubatus trained to follow a moving boat at different speeds and depths. We measured dive behavior (duration) and focused specifically on activity measures (fore-flipper stroking and overall dynamic body acceleration [ODBA], an overall measure of body motion), which may be proxies for metabolic expenditure. Sea lions appeared to increase efficiency while transiting at depths that approached 3 times their body diameters (mean depth $=151 \pm$ $1 \mathrm{~cm}$ SEM, $\mathrm{n}=87$ ). Although the response was not uniform for all tested scenarios, all of the observed significant adjustments to dive behavior and swimming mechanics supported an increased efficiency at this depth. An increase in transit speed (4.5 versus 3.5 knots [kn] surface speed) was associated with elevated flipper stroke frequencies $(+5 \%)$ and stroke output (ODBA stroke ${ }^{-1},+48 \%$ ). Sea lions transiting against the flow of a tidal current had reduced dive durations $(-10 \%)$, while total ODBA was consistently elevated (+8\% overall). This response to tidal flow was accompanied either by elevated ODBA stroke ${ }^{-1}(3.5 \mathrm{kn})$ or a parallel increase in stroking $(4.5 \mathrm{kn})$. Our data demonstrate that small changes in the physical environment affect transiting in Steller sea lions, and imply that altered prey fields or changing ocean conditions can carry energetic consequences.
\end{abstract}

KEY WORDS: Diving · Overall dynamic body acceleration · ODBA · Flipper stroking · Locomotion · Hydrodynamics $\cdot$ Foraging

Resale or republication not permitted without written consent of the publisher

\section{INTRODUCTION}

Locomotor activity (swimming and diving) is an important component of a marine mammal's energy budget (Karasov 1992). Otariid seals are central place foragers (Orians \& Pearson 1979) that commute to foraging patches from terrestrial haul-out sites, suggesting that costs to travel to prey patches may be as significant as foraging effort upon arrival (e.g. Insley et al. 2008). Further, the prolonged nursing periods for many otariid species (relative to other pinnipeds, Schulz \& Bowen 2004) likely limit the duration and increase the frequency of trips to sea for lactating females. Considerable research has focused on the energetics of otariid diving, particularly on the relationship between diving exercise and foraging effort. Many studies have de- scribed the energetic costs (e.g. Kooyman et al. 1981, Lavigne et al. 1986, Williams et al. 1991, Arnould et al. 1996, Williams 1999, Hastie et al. 2006, Fahlman et al. 2008), mechanics (e.g. Feldkamp 1987, Fish 1994, Williams 2001, Insley et al. 2008), and scheduling (e.g. Boyd et al. 1995, Boyd 1997, Horning \& Trillmich 1997, Thompson \& Fedak 2001, Costa et al. 2004) of dive bouts. On the other hand, studies directly addressing transit swimming are less numerous (Ponganis et al. 1990, Stelle et al. 2000, Chilvers et al. 2005, Insley et al. 2008), with many confined by experimental logistics to surface swimming only (Butler et al. 1992, Williams 1999, Rosen \& Trites 2002, Liwanag et al. 2009).

Altered ocean conditions (Trenberth \& Hurrell 1994, Learmonth et al. 2006) can have energetic consequences by directly affecting transit costs through 
changes in physical characteristics, such as ocean currents or ice patterns (Tynan \& DeMaster 1997, Baker 2007). However, changing local oceanographic properties can alter transit costs indirectly by affecting the persistence and location of prey patches (Costa \& Gales 2003). More distant or more widely distributed prey can be potentially compensated for by increasing the duration, distance, average transit speed, or frequency of trips to sea. All options associated with foraging and ocean conditions have energetic consequences, particularly for lactating females constrained to forage near breeding sites, which may ultimately contribute to population declines (Grémillet et al. 2006). It is therefore important to quantify the costs of transit swimming to assess the outcome of changes in swimming behavior on the time-energy budgets.

Transit swimming occurs at shallower depths than foraging dives, likely because of the frequent surfacing required for respiration to maintain high swimming speeds (Williams \& Kooyman 1985, Fish 1992). However, displacement wave action and potentially turbulent conditions near the air-water boundary create near-surface conditions associated with dramatically elevated hydrodynamic drag (e.g. Hertel 1966, Fish 1993, Vogel 1994). Drag observed near the water surface has been estimated to be 5 times greater than drag on a similar object traveling below a depth of 3 times body diameter (Hertel 1966), leading to the hypothesis that optimal swimming depths occur at, but not below, 3 times body diameter. Although this hypothesis is well established and has been incorporated into many hydrodynamic models (Fish 1993, 1998, Hughes 2004) and discussions of surface swimming limitations (Williams \& Kooyman 1985, Graham et al. 1987, Aigeldinger \& Fish 1995, Skrovan et al. 1999, Butler 2000), the hypothesis has rarely been investigated over a range of shallow subsurface swim depths (Yoda et al. 1999, Hughes 2004, Blake \& Chan 2007, Blake 2009).

Our goal was to determine whether an optimal depth for transit swimming exists in Steller sea lions Eumetopias jubatus by having trained animals follow a target at a specific depth and speed alongside a moving boat. We also examined the effect of increased swimming speed on locomotory patterns (e.g. flipper strokes taken, Williams et al. 2004). Finally, to consider the influence of transient local ocean conditions, we examined the effect of tidal currents on transiting Steller sea lions.

We quantified the effect of swimming depth, speed, and water current on transit swimming by comparing submergence durations, fore-flipper stroking frequency, and an integrated measure of body motion (overall dynamic body acceleration, ODBA; Wilson et al. 2006). The metric ODBA combines the acceleration due to body motion from each of the 3 dimensional axes, therefore integrating the acceleration arising from the number and amplitude of individual flipper beats (Wilson et al. 2006). There are indications that ODBA can serve as a proxy for field metabolic rate in several species (e.g. Wilson et al. 2006, Fahlman et al. 2008, Halsey et al. 2009, Gleiss et al. 2010), and may be a useful tool for assessing the relative magnitude of effects on the locomotory costs of Steller sea lions. Thus, our combined assessment of activity parameters and sea lion dive behavior allowed us to explore the potential energetic consequences of altered transiting conditions on this species.

\section{MATERIALS AND METHODS}

Animals. We studied 3 adult female Steller sea lions housed in purpose-built floating pens, located in a coastal inlet in British Columbia, Canada $\left(49^{\circ} 17^{\prime} 25^{\prime \prime} \mathrm{N}, 122^{\circ} 54^{\prime} 55^{\prime \prime} \mathrm{W}\right)$. Sea lions cooperated freely with all data collection, and were not restrained or confined for any trials. Two of the sea lions (F97SI and F97HA) were $12 \mathrm{yr}$ old, with mean weights of $220.2 \pm 0.5 \mathrm{~kg}(\mathrm{SEM} ; \mathrm{n}=36$ trial days) and $169.8 \pm 0.3$ $\mathrm{kg}(\mathrm{n}=21$ trial days) respectively. The third sea lion (F00BO) was 9 yr old, and averaged $143.9 \pm 0.3 \mathrm{~kg}(\mathrm{n}=$ 30 trial days). Maximal girths were $163.1 \pm 0.4,150.8 \pm$ 0.7 , and $137.6 \pm 0.4 \mathrm{~cm}$ for the 3 animals, respectively. All animal handling and experimental procedures were conducted in accordance with regulations of the Canadian Council on Animal Care (University of British Columbia animal use permit no. A04-0311), Department of Fisheries and Oceans Canada (MML 2007-001), and the Vancouver Aquarium.

Telemetry data. We monitored the sea lions with an Mk10v data logger (Wildlife Computers) mounted between the animals' shoulder blades using a removable harness. Each harness was fitted specifically to the individual animal, to minimize drag and any noise in the data associated with a loose-fitting harness. The logger archived depth, temperature, light level, wetdry state, velocity, and tri-axial acceleration. We quantified dive behavior via dive durations. We also documented swimming mechanics using acceleration data to detect fore-flipper stroking as well as calculate ODBA.

Acceleration was sampled at $16 \mathrm{~Hz}$ for surge (motion on the anterior-posterior axis) and sway (motion on the lateral axis), and $64 \mathrm{~Hz}$ for heave (motion on the dorso-ventral axis), with data collected in $\mathrm{m} \mathrm{s}^{-2}$ and divided by 9.8 for conversion into units of gravitational acceleration $(g)$. Body heave $(64 \mathrm{~Hz})$ detected individual fore-flipper strokes by sea lions underwater, which were computed as total strokes taken (over the entire $1 \mathrm{~km}$ trial) and stroke frequency (rate $\mathrm{min}^{-1}$ while sub- 
merged). ODBA ( $g$; Wilson et al. 2006) was determined from the 3-channel sum of dynamic acceleration, calculated as the absolute value difference between static (data smoothed with a $3 \mathrm{~s}$ running mean, per Shepard et al. 2008a) and total (unsmoothed) acceleration values at $16 \mathrm{~Hz}$. We computed both average ODBA (mean over the entire trial or relevant trial portion, if noted) and 2 integrated ODBA values. Sum ODBA was the per second total of ODBA over the entire trial (or trial portion if noted), while ODBA stroke ${ }^{-1}$ was integrated per flipper stroke at $16 \mathrm{~Hz}$ and represented body acceleration attributable to individual strokes.

Trial protocol. We measured swimming mechanics and dive behavior as outlined above in sea lions swimming at the water surface, and at $0.5 \times, 1 \times$, and $2 \times$ calculated optimal transit depth (OD $=3 \times$ body diameter, per Hertel 1966). OD for each sea lion was recalculated weekly to account for slight seasonal changes in body shape. Sea lions were instructed to swim alongside a research boat $(6.7 \mathrm{~m})$ for $1 \mathrm{~km}$ in an ocean inlet. This trial distance was divided to control for tidal effects: $500 \mathrm{~m}$ against the current (upcurrent) and $500 \mathrm{~m}$ with the current (downcurrent). The sea lions had been trained from an early age to follow floats (targets), and we affixed a target to the weighted end of a downrigger (suspended from the side of the boat) to control swimming depth for each trial.

The sea lions swam alongside the boat traveling at a surface speed of 3.5 knots $(\mathrm{kn})$ in each direction $\left(1.8 \mathrm{~m} \mathrm{~s}^{-1}\right.$ or $\left.6.5 \mathrm{~km} \mathrm{~h}^{-1}\right)$. This was absolute speed per GPS coordinates, versus effective speed, which includes water current. For this trial type, speed variability due to water current was $4.8 \%$ on average (range: 0.2 to $12.6 \%$ ). We selected this speed because it fell within the range of swim speed associated with minimum cost of transport for this species (1.7 to $2.1 \mathrm{~m} \mathrm{~s}^{-1}$; Rosen \& Trites 2002). A subset of trials ( $\mathrm{n}=5$ trials per depth for each sea lion F97SI and F00BO) was also performed outside this range of speed, at $4.5 \mathrm{kn}\left(2.3 \mathrm{~m} \mathrm{~s}^{-1}\right.$ or $8.3 \mathrm{~km} \mathrm{~h}^{-1}$ ). Speed variability due to water current for this trial type was $2.8 \%$ (range: 0.1 to $8.0 \%$ ). Speed and trial start and end points were measured via GPS (LMS-350A, Lowrance).

To assess the possibility that the harness and data loggers interfere with optimal swimming in Steller sea lions, we performed a subset of trials while the animals were not wearing their harnesses ( 3 trials each at $0.5 \times$ OD and $1 \times$ OD with F97SI and F97HA). Dive durations were measured manually with a stopwatch, while foreflipper strokes were counted visually. Unfortunately, visibility limitations prevented a manual count of flipper strokes at $2 \times \mathrm{OD}$.

Finally, we determined the swimming depth chosen voluntarily by our sea lions by monitoring the animals ( $\mathrm{n}=3$ ) as they swam without specific instruction regarding swim depth $\left(\mathrm{n}=5\right.$ trials animal $\left.{ }^{-1}\right)$. The boat speed was also matched to the swimming speed of each sea lion, such that the animal controlled both the depth and speed of these free swimming trials.

Statistics. Data were analyzed using SPSS statistical software (v.11.5.1). Univariate ANOVA was run to separately assess the influence of depth and transit speed on dive behavior (dive duration) and swimming mechanics (flipper stroking and ODBA). For this analysis, we nested 'DEPTH' and 'SPEED' within the 'ANIMAL ID' term to account for inter-individual variation on collected data. Paired $t$-tests compared variables from upcurrent versus downcurrent portions of the same trial. We applied Bonferroni's correction factor to $\mathrm{p}$ values for sequential and related tests (Rice 1989), and used leastsquares regression analyses to explore linear relationships between different measures of activity.

We tested for normality using the Shapiro-Wilk statistic, and confirmed homogeneity of variance using the modified Levene test. Data were transformed when necessary to meet the assumptions of parametric tests (transformations are noted in the Results). Statistical significance was set at $\alpha=0.05$, and all values are presented as mean $\pm \mathrm{SEM}$.

\section{RESULTS}

\section{Comparison of acceleration measures}

All 3 sea lions used a constant stroking pattern while transiting alongside the moving boat (Fig. 1). Not surprisingly, sum ODBA was positively correlated with total number of flipper strokes taken during a $1 \mathrm{~km}$ swim at $3.5 \mathrm{kn}$. What was surprising, however, was how little, if any, of the variation in acceleration could be explained by number of flipper strokes at $3.5 \mathrm{kn}\left(\mathrm{r}^{2}=0.29\right.$, $\mathrm{p}<0.001$, Fig. 2) and $4.5 \mathrm{kn}\left(\mathrm{r}^{2}=0.10, \mathrm{p}=0.07\right.$, Fig. 2). At $3.5 \mathrm{kn}$, the number of flipper strokes was best reflected in the heave axis of dynamic acceleration $\left(\mathrm{r}^{2}=\right.$ $0.37, \mathrm{p}<0.001)$ followed by surge $\left(\mathrm{r}^{2}=0.25, \mathrm{p}<0.001\right)$ and sway $\left(\mathrm{r}^{2}=0.06, \mathrm{p}=0.093\right)$, while acceleration per flipper stroke (ODBA stroke ${ }^{-1}$ ) declined as flipper stroke frequency increased at both transit speeds (semi-log plots in Fig. 3; 3.5 kn, $\mathrm{r}^{2}=0.23$, p $<0.001$; $\left.4.5 \mathrm{kn}, \mathrm{r}^{2}=0.49, \mathrm{p}<0.001\right)$.

\section{Effects of transit depth}

For Steller sea lions transiting at $3.5 \mathrm{kn}$ (a speed associated with minimum cost of transport measurements) dive behavior (duration) and whole-body activity measures (average and sum ODBA, and ODBA stroke ${ }^{-1}$ ) were consistent between tested depths (Fig. 4A,C,D). 


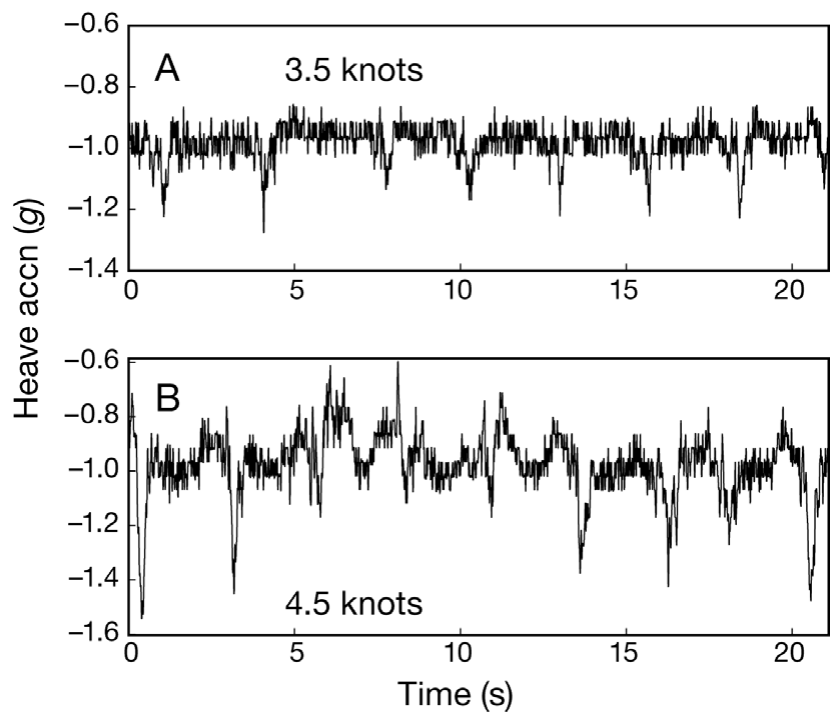

Fig. 1. Eumetopias jubatus. Example of raw heave acceleration data (accn) during a period in which a Steller sea lion (F97SI) was swimming at (A) $3.5 \mathrm{kn}$ and (B) $4.5 \mathrm{kn}$ at $1 \times$ optimal depth (OD)

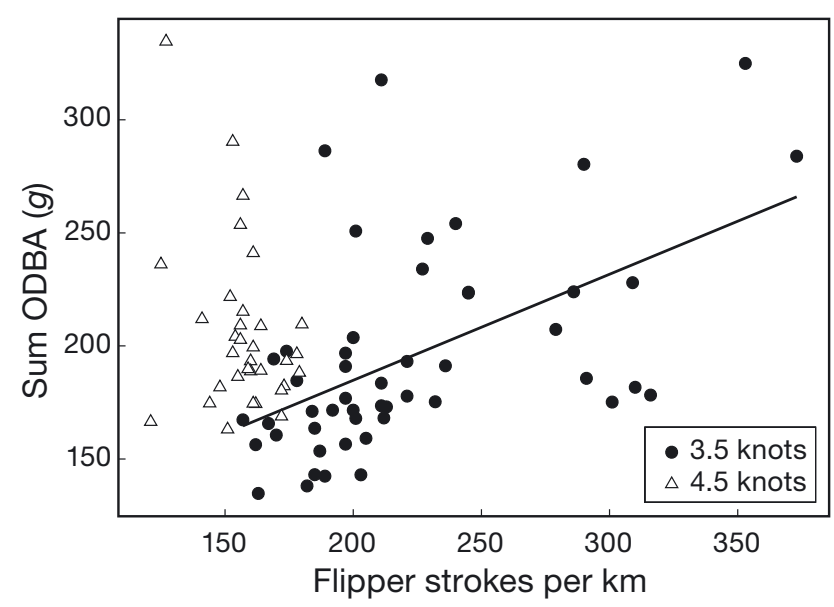

Fig. 2. Eumetopias jubatus. Sum overall dynamic body acceleration (ODBA) versus sum flipper strokes over $1 \mathrm{~km}$ transit swims by Steller sea lions. Per second ODBA was summed across the entire trial. $\bullet$ : trials at $3.5 \mathrm{kn}$ by $\mathrm{n}=3$ sea lions (regression $\left.\mathrm{r}^{2}=0.29, \mathrm{p}<0.001\right) . \Delta$ : trials at $4.5 \mathrm{kn}$ by $\mathrm{n}=2$ sea lions

Only fore-flipper stroking (strokes taken trial ${ }^{-1}$, mean stroke frequency) differed between transit depths at this speed (total strokes: $F_{8,41}=12.23, \mathrm{p}<0.0001,1 / \mathrm{x}$ transformed; stroke frequency: $F_{8,41}=26.47, \mathrm{p}<0.0001$, $1 / x$ transformed). Fore-flipper stroking was lowest at $1 \times$ OD $(211 \pm 11$ strokes over $1 \mathrm{~km}, 25.4 \pm 1.2$ strokes $\mathrm{min}^{-1}$ ). For the former measure, this was an $8 \%$ average savings compared to $2 \times \mathrm{OD}$, and a $5 \%$ savings compared to $0.5 \times$ OD (Fig. 4B).

A subset of trials conducted without the telemetrybearing harness $(\mathrm{n}=2$ sea lions swimming at $0.5 \times \mathrm{OD}$ and $1 \times$ OD only) provided some further insight into the

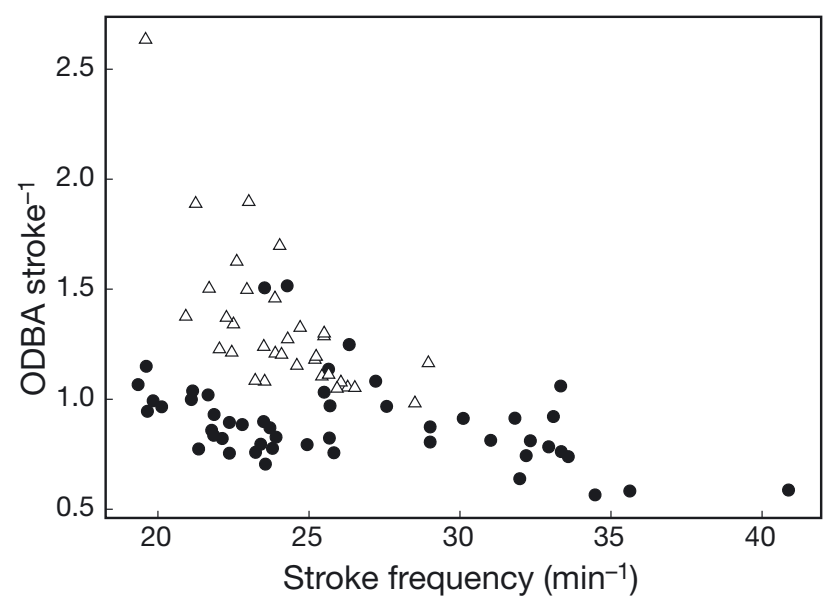

Fig. 3. Eumetopias jubatus. Overall dynamic body acceleration (ODBA) integrated per flipper stroke for each $1 \mathrm{~km}$ trial was negatively correlated with flipper stroke frequency $\left(\mathrm{min}^{-1}\right)$ at both $3.5 \mathrm{kn}(\bullet)$ and $4.5 \mathrm{kn}$ speeds $(\Delta)$. Data are presented from Steller sea lions transiting alongside a moving boat at 3 fixed depths ( $\mathrm{n}=3$ for $3.5 \mathrm{kn}$ trials, $\mathrm{n}=2$ for $4.5 \mathrm{kn}$ trials). When ODBA stroke ${ }^{-1}$ was log-transformed, relationships were significantly linear at both $3.5 \mathrm{kn}\left(\mathrm{r}^{2}=0.23, \mathrm{p}<0.001\right)$ and $4.5 \mathrm{kn}$ $\left(\mathrm{r}^{2}=0.49, \mathrm{p}<0.001\right)$

influence of depth on transit swimming in Steller sea lions. Unfortunately, we could not calculate additional activity parameters in the absence of animal-borne telemetry equipment for this trial scenario. However, under these conditions, $1 \times$ OD produced the longest average dive durations ( $17 \pm 1 \mathrm{~s}, 29 \%$ overall elevation beyond $0.5 \times \mathrm{OD}_{i} F_{3,8}=7.06, \mathrm{p}=0.012$ ). Although a depth effect on flipper stroke frequency was not statistically significant, sea lions transiting at $1 \times$ OD also required fewer flipper strokes overall to swim $1 \mathrm{~km}$ ( $20 \%$ fewer versus $0.5 \times \mathrm{OD}$ ).

Beyond the uppermost swim speed associated with minimum cost of transport in this species $(4.5 \mathrm{kn})$, dive durations were longest at $1 \times \mathrm{OD}\left(15 \pm 1 \mathrm{~s}, F_{5,28}=4.74\right.$, $\mathrm{p}=0.003$, log-transformed), being $15 \%$ elevated beyond $0.5 \times \mathrm{OD}$, and $18 \%$ beyond $2 \times \mathrm{OD}$ on average. At this speed, stroke frequency was lowest $(23.2 \pm 0.6$ strokes $\mathrm{min}^{-1}, F_{5,27}=4.42, \mathrm{p}=0.005$ ) and ODBA stroke $^{-1}$ was greatest $\left(1.43 \pm 0.13 \mathrm{~g}\right.$ stroke ${ }^{-1}, F_{5,27}=$ 6.49, $\mathrm{p}=0.004,1 / \mathrm{x}$ transformed, Fig. $4 \mathrm{D})$ at $1 \times \mathrm{OD}$. Indeed, sea lions transiting at $1 \times$ OD generated $\sim 5 \%$ more acceleration per flipper stroke compared to those transiting at any other depth. There was also a significant overall effect of transit depth on both the average $\left(F_{5,27}=4.62, p=0.004,1 / x^{3}\right.$ transformed, Fig. $\left.4 \mathrm{C}\right)$ and sum ODBA $\left(F_{5,27}=6.43, \mathrm{p}=0.0005,1 / x\right.$ transformed $)$ for the $4.5 \mathrm{kn}$ trials. However, there was considerable inter-individual variability in the response for both measures, and no consistent patterns associated with transit depth emerged. 

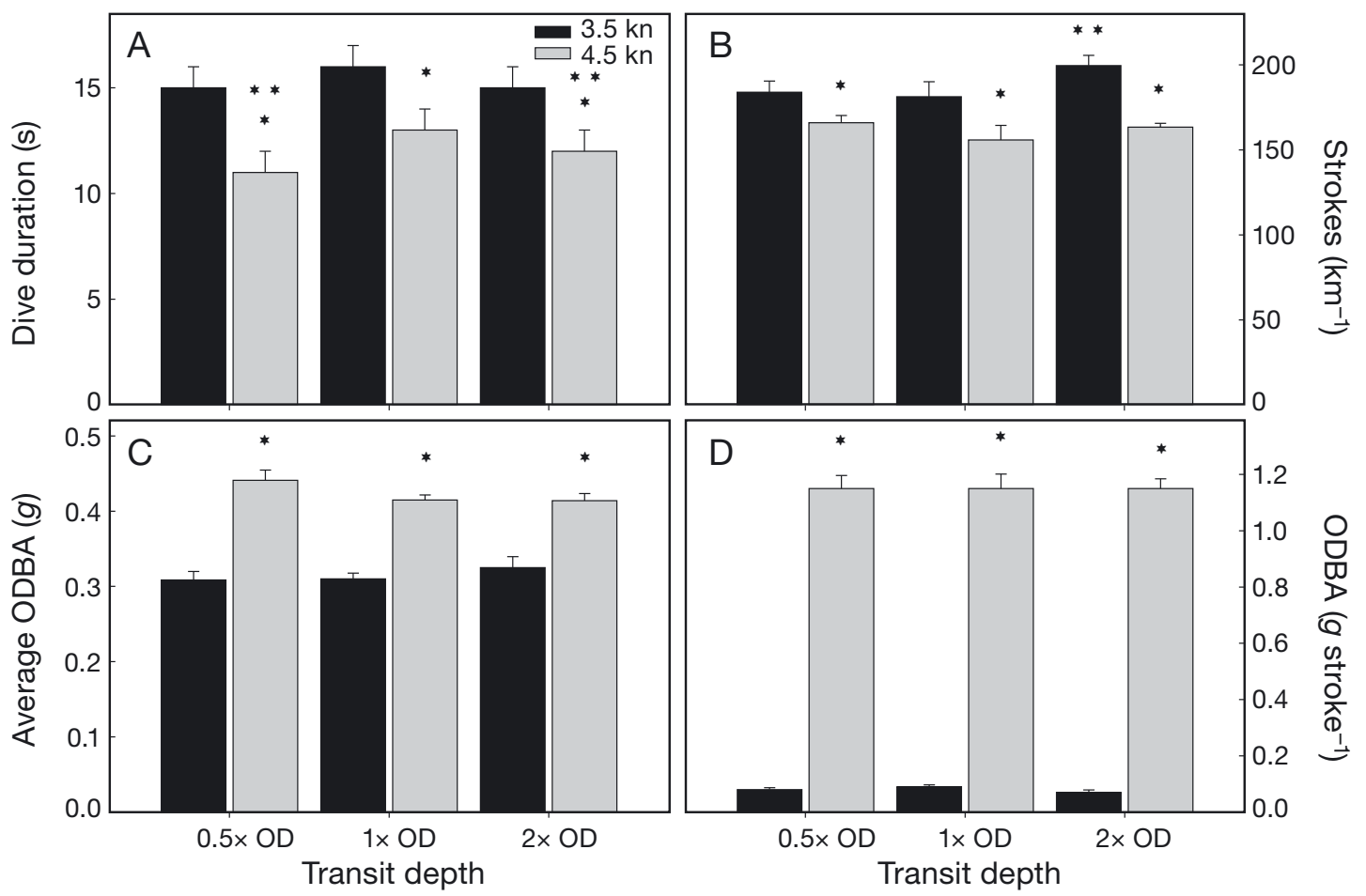

Fig. 4. Eumetopias jubatus. Dive and activity parameters (mean \pm SEM) for a Steller sea lion (F00BO) transiting at 3 depths alongside a boat moving at 3.5 (dark bars) or $4.5 \mathrm{kn}$ (light bars). Transit depths were defined as multiples of hypothesized optimal depth (OD) equal to $3 \times$ body diameter. (A) Dive durations, (B) fore-flipper strokes $\mathrm{km}^{-1},(\mathrm{C})$ average overall dynamic body acceleration (ODBA) over the entire trial, and (D) ODBA stroke ${ }^{-1}$ (ODBA integrated per stroke). Asterisks represent statistical significance for the complete ( $\mathrm{n}=3$ sea lions) data set. For a given variable, ${ }^{*}$ denotes post hoc significance between transit speeds, while ${ }^{* *}$ denotes significant post hoc discrepancy between a given transit depth, compared to $1 \times \mathrm{OD}$

The mean values of swim depths chosen by freeswimming Steller sea lions were extremely close to their calculated optimal transit depths (mean: $0.2 \%$ difference, median: $-1.9 \%$ difference). Surprisingly, the sea lions could not keep pace with the research boat traveling at $3.5 \mathrm{kn}$ over a $1 \mathrm{~km}$ distance when they swam entirely on the surface.

\section{Effect of speed and harness}

Mean dive duration was depressed by $3 \mathrm{~s}$ on average at increased swim speed ( 4.5 versus $3.5 \mathrm{kn}_{i} F_{4,79}=7.42$, $\mathrm{p}<0.001$, log-transformed). This depression was attenuated (only 2 s) in $1 \times$ OD trials. These faster trials required higher flipper stroke frequencies $(24.1 \pm 0.4$ strokes $\left.\min ^{-1}, F_{4,78}=35.51, \mathrm{p}<0.001\right)$ to cover the $1 \mathrm{~km}$ trial distance, and this occurred in conjunction with an overall increase in acceleration (Fig. 1). Both average $(0.46 \pm 0.01 \mathrm{~g})$ and sum ODBA $(206 \pm 6 \mathrm{~g})$ were elevated at faster transit speeds $\left(F_{4,78}=23.91, \mathrm{p}<0.001\right.$, $F_{4,78}=8.11, \mathrm{p}<0.001,1 / x$ transformed, respectively; Fig. $4 \mathrm{C}$ ), and this elevation was greater for average ODBA (43 versus $13 \%$ elevation of sum ODBA overall).
ODBA stroke ${ }^{-1}$ was $48 \%$ greater than in slower trials, averaging $1.3 \pm 0.06 \mathrm{~g}$ stroke $^{-1}\left(F_{4,78}=29.17, \mathrm{p}<0.001\right.$, log-transformed; Fig. 4D).

When speed was held constant ( $3.5 \mathrm{kn})$, the harness worn by the sea lion had an inconsistent and insignificant effect on dive duration. However, the differences between mean dive durations for the optimal and shallow swim depths were greater in the absence of a harness (F97SI 20\%; F97HA 42\% elevation). Flipper stroking generally decreased when the sea lions swam without a harness (185 \pm 13 total strokes), and the magnitude of this decrease was least at $1 \times$ OD. For example, total flipper strokes $\mathrm{km}^{-1}$ only decreased by $10 \%$ in $1 \times$ OD trials for F97SI (versus a $23 \%$ at $0.5 \times \mathrm{OD}$ ), and only by $6 \%$ for F97HA (versus $39 \%$ at $0.5 \times \mathrm{OD}$ ).

\section{Water current}

Sea lions transiting downcurrent spent more time underwater (18 versus $16 \mathrm{~s}$ on average when swimming upcurrent) at $3.5 \mathrm{kn}$. This was a $12.5 \%$ elevation beyond mean dive duration transiting upcurrent (with harness: $t=3.27, \mathrm{df}=49, \mathrm{p}=0.004$, log-transformed). 
This significant difference in dive duration was also noted during $4.5 \mathrm{kn}$ trials ( $8 \%$ difference, $t=2.36$, $\mathrm{df}=33, \mathrm{p}=0.048, \log$-transformed). Direction of the water current did not affect flipper stroking (either total strokes or stroke frequency) of Steller sea lions transiting at $3.5 \mathrm{kn}$ (Fig. 5B). However, both measures of flipper stroking significantly increased (by $\sim 5 \%$ ) during the upcurrent portion of faster $(4.5 \mathrm{kn}$ ) trials (stroke frequency: $t=-2.85, \mathrm{df}=32, \mathrm{p}=0.016$; strokes taken: $t=$ $-2.74, \mathrm{df}=32, \mathrm{p}=0.02$, Fig. 5B). Acceleration measures were also significantly higher when sea lions were transiting against a tidal current, regardless of speed (e.g. $8 \%$ mean ODBA increase at $3.5 \mathrm{kn}, t=-4.10, \mathrm{df}=48$, $\mathrm{p}=0.0005$; Fig. 5C). At $3.5 \mathrm{kn}$ only, ODBA stroke ${ }^{-1}$ was elevated during upcurrent swimming $(t=-2.76, \mathrm{df}=48$, $\mathrm{p}=0.024, \log$-transformed; Fig. 5D).

\section{DISCUSSION}

It is logistically difficult to measure the cost of transport in marine mammals directly. However, indirect measures such as activity provide useful information about locomotion, and such measurements are possible on free-ranging animals. All movement requires energy, implying that remotely monitored animal activity could also be used to quantify locomotory energetic costs. For example, some studies have demonstrated the relationship between flipper stroking (Williams et al. 2004) and tri-axial dynamic acceleration (ODBA; Wilson et al. 2006, Halsey et al. 2009) and metabolic expenditure in swimming or running animals. Although neither method has previously been calibrated for Steller sea lions, some correlation between ODBA and diving metabolic rate has been noted (Fahlman et al. 2008). We documented the relative magnitude of changes in these 2 logical proxies of swimming effort in Steller sea lions facing controlled adjustments in swim speed, swim depth, and water current.

Our data can be used to consider the manner in which Steller sea lions adjust stroking patterns to accommodate increased power output requirements. Moreover, the consideration of flipper stroking and ODBA in parallel reveals the conditions under which each metric is most meaningful for describing transit swimming in this species. For a small change in the physical environment (e.g. a transiting depth outside of the optimal range), sea lions respond by increasing flipper stroke frequency. This was the only adjustment to stroking patterns made at the slower tested speed (i.e. no significant changes in ODBA were noted). At a faster speed, a similar change in the physical environment (i.e. transit depth) was also met by increased
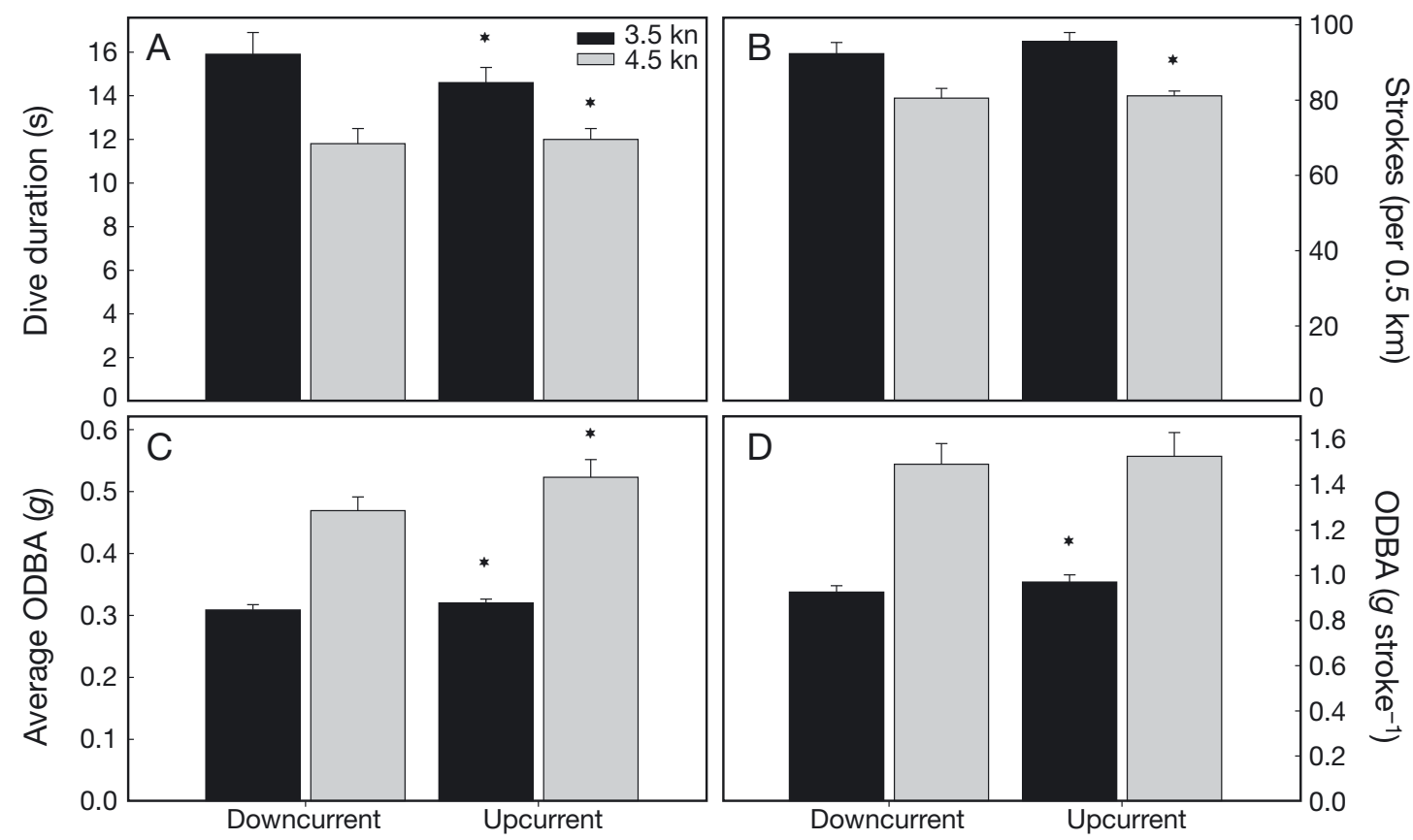

Fig. 5. Eumetopias jubatus. Dive and activity parameters (mean \pm SEM) for a Steller sea lion (F00BO) transiting alongside a moving boat at 3.5 (dark bars) or $4.5 \mathrm{kn}$ (light bars). (A) Dive durations, (B) fore-flipper strokes, (C) average overall dynamic body acceleration (ODBA), and (D) ODBA stroke ${ }^{-1}$ (ODBA integrated per stroke) are presented for both the upcurrent and downcurrent trial portions. Asterisks represent statistical significance for the complete ( $\mathrm{n}=2$ sea lions) data set. For a given variable, ${ }^{*}$ denotes a significant ( $t$-test) response to direction of tidal flow 
stroke frequency, but this adjustment occurred at the expense of ODBA generated per stroke. In response to a larger change (e.g. a comparison of the 2 swim speeds), sea lions increased both the frequency and output (ODBA stroke ${ }^{-1}$ ) of flipper strokes.

While our data demonstrate that even small changes in the physical environment can significantly affect stroking patterns in transiting Steller sea lions, it is clear that the 2 activity measures examined do not respond uniformly. Although flipper stroking and ODBA are presumed to correlate, 2 exceptions emerge from our dataset. First, total flipper strokes taken over $1 \mathrm{~km}$ of transiting correlated with ODBA (summed over the entire trial) only at the $3.5 \mathrm{kn}$ transit speed, and not at the faster speed (Fig. 2). No correlations between average ODBA and flipper stroke frequencies measured over the trial period were noted. Second, the average body acceleration attributable to individual strokes (ODBA stroke ${ }^{-1}$ ) increased sharply as the mean frequency of stroking slowed (Fig. 4). This suggests that sea lions modulate the amplitude of stroking or its translation into surge with the period of the stroke cycle. It remains to be seen whether any relationship exists between these 2 acceleration metrics during vertical diving in otariids (e.g. Shepard et al. 2008b, Wilson et al. 2008).

It is clear that flipper stroke frequencies do not provide a complete picture of stroking patterns for Steller sea lions. In addition to stroking frequency, power output of stroking activity depends on complex stroking kinematics, such as angle of attack. Variation in any additional components of power output is likely associated with parallel changes in energetic cost, which is not reflected in the frequency measure. Changes in stroke amplitude were suggested by our centermounted accelerometer only at low resolution, and not at all for angle of attack; this problem might be resolved by placement of a device directly on the flipper. Conversely, there was a large proportion of ODBA not explained by variation in flipper stroking. The reason for this scatter is unclear, but could be the result of differences in swim speed relative to water flow (we controlled for ground speed only). Compared to terrestrial locomotion, there are also several unique features of 3-dimensional aquatic movement that could affect acceleration metrics. For example, aquatic animals can glide, and they exhibit varied effort for a given ascent/ descent distance due to positive/negative buoyancy. For this study, we expect these effects to cancel out over the entire trial, but they could contribute to the scatter noted in the data. Further, hydrofoil-based lift and maneuvering can translate power output from 1 axis of motion to another, a feature which is potentially relevant to the development of ODBA as a proxy for aquatic locomotory effort.

\section{Transit depth}

It is well-documented that the energetic efficiency and speed of an animal swimming near the air-water surface interface are diminished by drag (e.g. Hertel 1966, Fish 1996). Near-surface swimming generates bow and stern interaction waves which set a 'maximum hull speed' derived from body length (Prange \& Schmidt-Nielsen 1970, Fish 1996). Surface-swimming animals rarely exceed maximum hull speed, except by a distinct adjustment to their locomotory pattern (Aigeldinger \& Fish 1995, Johansson \& Lauder 2004). Steller sea lions appear to be no exception, as demonstrated by their inability to keep pace at the surface with our boat traveling $3.5 \mathrm{kn}$ over a $1 \mathrm{~km}$ distance.

Overall, our results suggest that animals can maximize transit efficiency, and possibly realize a metabolic saving (Williams et al. 2004, Fahlman et al. 2008) by swimming at depths of about 3 times body diameter, compared to other tested swim depths. Although the effects were not uniform across all trial scenarios (different speeds, harness versus harness-free), all observed significance in parameters of swimming mechanics supports an increased efficiency at OD. One consistent difference observed at both trial speeds was that sea lions swam at OD with a reduced stroke frequency compared to other depths.

In addition to the noted effects on stroking patterns, we also found that altered transit depth was associated with behavioral changes. In 2 of the 3 transit scenarios, optimal transit depth produced the longest mean dive durations. The behavioral evidence supporting the existence of an optimal transit depth is strengthened by the observation that sea lions allowed to set their own transit schedule chose to swim at depths centered around their calculated OD (mean: $+0.2 \%$ difference, median: $-1.9 \%$ difference). With the exception of the largest individual, actual swim depth always fell within $\pm 11 \%$ of calculated OD (actual range +10.8 to $-10.6 \%$ difference). Although trials for the largest animal still demonstrated that chosen swim depth was centered at OD (mean: $-3.4 \%$ difference, median: $-4.5 \%$ difference), the range was much broader $(+22.3$ to $-24.4 \%$ difference), although this only represented a change in depth up to $\pm 50 \mathrm{~cm}$.

\section{Swim speed}

Hydrodynamic drag forces increase as an exponential function of swim speed, resulting in species- and size-specific speeds at which the costs of transport are minimized (e.g. Williams \& Kooyman 1985, Feldkamp 1987, Rosen \& Trites 2002). A previous study estimated that minimal cost of transport occurred at 1.7 
to $2.1 \mathrm{~m} \mathrm{~s}^{-1}$ swim speeds (Rosen \& Trites 2002) for young Steller sea lions in a flume. Our experimental setup permitted an alternate evaluation of the effects of swim speed without the constraints of a testing tank.

In our study, the additional energetic cost of increased swimming speed was manifested as elevated flipper stroke frequencies and elevated flipper stroke output (amplitude or translation into forward motion) over $4.5 \mathrm{kn}$ trials compared to $3.5 \mathrm{kn}$ trials. Behaviorally, this was manifested by significantly depressed mean dive durations for sea lions transiting at speeds beyond the minimum cost of transport. These data provide further evidence that measurable metabolic costs do result from elevated swim speeds under natural conditions. Our data therefore suggest that it would be more energetically efficient for sea lions to maintain optimum transit speeds (direct costs) at the expense of time spent foraging (indirect costs arising from decreased foraging time) when distributions of prey fields (e.g. foraging areas become farther apart or farther from shore; Perry et al. 2005) are altered by environmental conditions.

\section{Ocean conditions}

While most investigations of transit swimming involving marine mammals either test animals in a static environment or assume a static environment to simplify calculations, marine mammals in the wild must contend with dynamic oceanographic conditions. Tidal flow generated natural swim speed variability in our study, although this variability was small (e.g. it averaged $<5 \%$ for $3.5 \mathrm{kn}$ trials). Nonetheless, tidal currents did impact the effective swim speed of sea lions (versus absolute speed based on GPS coordinates), and this speed effect contributes to our findings. In our study, Steller sea lions responded to changes in water current associated with tides by altering both stroking patterns and their swimming behavior. Average and sum ODBA were elevated at both speeds for sea lions swimming against a tidal current. Flipper stroke frequency increased during the upcurrent portion of $4.5 \mathrm{kn}$ trials, while flipper stroke output (ODBA stroke ${ }^{-1}$ ) was elevated during this portion of $3.5 \mathrm{kn}$ trials. This demonstration of greater stroke amplitude modulation at slower swimming speeds could reflect either a speed-dependent change in capacity or adjustment in strategy. Our findings further suggest that upcurrent swimming necessitates generating greater propulsive output to overcome water flow, and that animals swimming upcurrent incur greater metabolic expenditures (Williams et al. 2004, Fahlman et al. 2008). This is supported by our observation that sea lions transiting upcurrent also had generally shorter $(10 \%$ on average) dive durations.
Tidal currents tend to be strongest near shore and weaken as an animal travels farther out to sea. Juvenile Steller sea lions rely critically on near-shore areas as they develop into mature divers (Raum-Suryan et al. 2004) and are therefore likely to be affected by tidal currents during the entirety of transit and foraging efforts. Summer maternal attendance patterns suggest that trips to sea are only slightly longer, and presumably farther from haul-outs than those of juveniles (Milette \& Trites 2003), implying that they may encounter similar interference from tides. By winter, however, lactating females embark on considerably longer trips to sea over greater home ranges (Merrick \& Loughlin 1997), and likely only contend with tidal currents while leaving and returning to their haul-outs.

In addition to near-shore currents, there are also offshore cyclonic and anticylonic mesoscale eddies that can vary over time scales of weeks to months (e.g. Miller et al. 2005), as well as seasonal and interannual shifts in major currents that cross entire ocean basins (e.g. Alaskan Stream; Onishi \& Ohtani 1999). Such variability in ocean circulation is well documented in the distribution range of Steller sea lions (Hayward 1997, Benson \& Trites 2002, Trites et al. 2007) and, as we have demonstrated, could energetically impact animals transiting to foraging areas or migrating to seasonal feeding arenas.

\section{CONCLUSIONS}

The locomotory patterns of Steller sea lions responded to ocean conditions in a proxy-field setting. We examined locomotion by focusing specifically on activity measures which may be proxies for metabolic expenditure (fore-flipper stroking and ODBA), and our data suggest that even small changes in ocean condition could affect transit costs in Steller sea lions. Our parallel analysis of flipper stroking and ODBA revealed that the 2 metrics are not equivalent for describing transit swimming in this species. Specifically, sea lions appeared to increase efficiency while transiting at depths that approached 3 times their body diameters. We noted that changes in flipper stroking (such as beat frequency) occurred in response to swim depth before changes in ODBA could be detected. On the other hand, we noted that stroke output (ODBA stroke $^{-1}$ ) was the most consistently increased variable when sea lions swam against the flow of a tidal current. The sometimes distinct responses of these 2 activity metrics, coupled with the limited correlation we noted between them in our dataset, revealed that each could be most meaningful under different conditions. We therefore stress that future studies consider the distinct features of these 2 metrics when interpreting data. 
Acknowledgements. Funding was provided to the North Pacific Universities Marine Mammal Research Consortium by the North Pacific Marine Science Foundation and the National Oceanographic and Atmospheric Administration. We sincerely appreciate the assistance of the trainers and technical and administrative staff at the Open Water Research Station and the Vancouver Aquarium. The technical assistance of $\mathrm{M}$. Horning regarding the telemetry equipment is gratefully acknowledged. This manuscript was significantly improved by comments from the reviewers.

\section{LITERATURE CITED}

Aigeldinger T, Fish F (1995) Hydroplaning by ducklings: overcoming limitations to swimming at the water surface. J Exp Biol 198:1567-1574

Arnould JPY, Boyd IL, Speakman JR (1996) The relationship between foraging behaviour and energy expenditure in Antarctic fur seals. J Zool (Lond) 239:769-782

Baker JD (2007) Post-weaning migration of northern fur seal Callorhinus ursinus pups from the Pribilof Islands, Alaska. Mar Ecol Prog Ser 341:243-255

Benson AJ, Trites AW (2002) Ecological effects of regime shifts in the Bering Sea and eastern North Pacific Ocean. Fish Fish 3:95-113

Blake RW (2009) Biological implications of the hydrodynamics of swimming at or near the surface and in shallow water. Bioinspir Biomim 4:015004

Blake RW, Chan KHS (2007) Swimming in the upside down catfish Synodontis nigriventris: it matters which way is up. J Exp Biol 210:2979-2989

Boyd IL (1997) The behavioural and physiological ecology of diving. Trends Ecol Evol 12:213-217

Boyd IL, Reid K, Bevan RM (1995) Swimming speed and allocation of time during the dive cycle in Antarctic fur seals. Anim Behav 50:769-784

Butler PJ (2000) Energetic costs of surface swimming and diving of birds. Physiol Biochem Zool 73:699-705

Butler PJ, Woakes AJ, Boyd IL, Kanatous S (1992) Relationship between heart rate and oxygen consumption during steady-state swimming in California sea lions. J Exp Biol 170:35-42

Chilvers BL, Wilkinson IS, Duignan PJ, Gemmell NJ (2005) Summer foraging areas for lactating New Zealand sea lions Phocarctos hookeri. Mar Ecol Prog Ser 304:235-247

Costa DP, Gales NJ (2003) Energetics of a benthic diver: seasonal foraging ecology of the Australian sea lion, Neophoca cinerea. Ecol Monogr 73:27-43

Costa DP, Kuhn CE, Weise MJ, Shaffer SA, Arnould JPY (2004) When does physiology limit the foraging behaviour of freely diving mammals? Int Congr Ser 1275:359-366

Fahlman A, Svärd C, Wilson R, Rosen DAS, Trites AW (2008) Activity and diving metabolism correlate in Steller sea lion Eumetopias jubatus. Aquat Biol 2:75-84

Feldkamp SD (1987) Swimming in the California sea lion: morphometrics, drag and energetics. J Exp Biol 131:117-135

Fish FE (1992) Aquatic locomotion. In: Tomasi TE, Horton TH (eds) Mammalian energetics: interdisciplinary views of metabolism and reproduction. Cornell University Press, Ithaca, NY, p 34-63

Fish FE (1993) Power output and propulsive efficiency of swimming bottlenose dolphins (Tursiops truncatus). J Exp Biol 185:179-193

Fish FE (1994) Influence of hydrodynamic design and propulsive mode on mammalian swimming energetics. Aust J Zool 42:79-101
Fish FE (1996) Transitions from drag-based to lift-based propulsion in mammalian swimming. Am Zool 36:628-641

Fish FE (1998) Comparative kinematics and hydrodynamics of odontocete cetaceans: morphological and ecological correlates with swimming performance. J Exp Biol 201: $2867-2877$

> Gleiss AC, Dale JJ, Holland KN, Wilson RP (2010) Accelerating estimates of activity-specific metabolic rate in fishes: testing the applicability of acceleration data-loggers. J Exp Mar Biol Ecol 385:85-91

Graham JB, Lowell WR, Rubinoff I, Motta J (1987) Surface and subsurface swimming of the sea snake Pelamis platurus. J Exp Biol 127:27-44

> Grémillet D, Pichegru L, Siorat F, Georges JY (2006) Conservation implications of the apparent mismatch between population dynamics and foraging effort in French northern gannets from the English Channel. Mar Ecol Prog Ser 319:15-25

Halsey LG, Shepard EL, Quintana F, Gomez Laich A, Greem JA, Wilson RP (2009) The relationship between oxygen consumption and body acceleration in a range of species. Comp Biochem Physiol A Mol Integr Physiol 152:197-202

Hastie GD, Rosen DAS, Trites AW (2006) Studying diving energetics of trained Steller sea lions in the open ocean. In: Trites AW, Atkinson S, DeMaster DP, Fritz LW, Gelatt TS, Rea LD, Wynne KM (eds) Sea lions of the world. Alaska Sea Grant College Program, University of Alaska, Fairbanks, AK, p 193-204

> Hayward TL (1997) Pacific Ocean climate change: atmospheric forcing, ocean circulation and ecosystem response. Trends Ecol Evol 12:150-154

Hertel H (1966) Structure, form and movement. Rheinhold, New York, NY

> Horning M, Trillmich F (1997) Ontogeny of diving behaviour in the Galápagos fur seal. Behaviour 134:1211-1257

> Hughes NF (2004) The wave-drag hypothesis: an explanation for size-based lateral segregation during the upstream migration of salmonids. Can J Fish Aquat Sci 61:103-109

> Insley SJ, Robson BW, Yack T, Ream RR, Burgess WC (2008) Acoustic determination of activity and flipper stroke rate in foraging northern fur seal females. Endang Species Res $4: 147-155$

Johansson LC, Lauder GV (2004) Hydrodynamics of surface swimming in leopard frogs (Rana pipiens). J Exp Biol 207: 3945-3958

Karasov WH (1992) Daily energy expenditure and the cost of activity in mammals. Am Zool 32:238-248

Kooyman GL, Castellini MA, Davis RW (1981) Physiology of diving in marine mammals. Annu Rev Physiol 43:343-356

Lavigne DM, Innes S, Worthy GAJ, Kovacs KM, Schmitz OJ, Hickie JP (1986) Metabolic rates of seals and whales. Can J Zool 64:279-284

Learmonth JA, MacLeod CD, Santos MB, Pierce GJ, Crick HQP, Robinson RA (2006) Potential effects of climate change on marine mammals. Oceanogr Mar Biol Annu Rev 44:431-464

Liwanag HEM, Williams TM, Costa DP, Kanatous SB, Davis RW, Boyd IL (2009) The effects of water temperature on the energetic costs of juvenile and adult California sea lions (Zalophus californianus): the importance of skeletal muscle thermogenesis for thermal balance. J Exp Biol 212: 3977-3984

Merrick RL, Loughlin TR (1997) Foraging behavior of adult female and young-of-year Steller sea lions in Alaskan waters. Can J Zool 75:776-786

Milette LL, Trites AW (2003) Maternal attendance patterns of Steller sea lions (Eumetopias jubatus) from stable and declining populations in Alaska. Can J Zool 81:340-348 
Miller AJ, Neilson DJ, Lorenzo ED, Kim HJ and others (2005) Interdecadal changes in mesoscale eddy variance in the Gulf of Alaska circulation: possible implications for the Steller sea lion decline. Atmos-Ocean 43:231-240

Onishi H, Ohtani K (1999) On seasonal and year to year variation in flow of the Alaskan Stream in the central North Pacific. J Oceanogr 55:597-608

Orians GH, Pearson NE (1979) On the theory of central place foraging. In: Horn DJ, Mitchell RD, Stairs GR (eds) Analysis of ecological systems. Ohio State University Press, Columbus, OH, p 154-177

Perry AL, Low PJ, Ellis JR, Reynolds JD (2005) Climate change and distribution shifts in marine fisheries. Science 308: 1912-1915

Ponganis PJ, Ponganis EP, Ponganis KV, Kooyman GL, Genry RL, Trillmich F (1990) Swimming velocities in otariids. Can J Zool 68:2105-2112

Prange HD, Schmidt-Nielsen K (1970) The metabolic cost of swimming in ducks. J Exp Biol 53:763-777

Raum-Suryan KL, Rehberg MJ, Pendleton GW, Pitcher KW, Gelatt TS (2004) Development of dispersal, movement patterns, and haul-out use by pup and juvenile Steller sea lions (Eumetopias jubatus) in Alaska. Mar Mamm Sci 20: $823-850$

Rice WR (1989) Analyzing tables of statistical tests. Evolution 43:223-225

Rosen DAS, Trites AW (2002) Cost of transport in Steller sea lions, Eumetopias jubatus. Mar Mamm Sci 18:513-524

Schulz TM, Bowen WD (2004) Pinniped lactation strategies: evaluation of data on maternal and offspring life history traits. Mar Mamm Sci 20:86-114

Shepard ELC, Wilson RP, Halsey LG, Quintana F and others (2008a) Derivation of body motion via appropriate smoothing of acceleration data. Aquat Biol 4:235-241

Shepard ELC, Wilson RP, Quintana F, Gómez Laich A and others (2008b) Identification of animal movement patterns using tri-axial accelerometry. Endang Species Res 10:47-60

Skrovan RC, Williams TM, Berry PS, Moore PW, Davis RW (1999) The diving physiology of bottlenose dolphins (Tursiops truncatus) II. Biomechanics and changes in buoyancy at depth. J Exp Biol 202:2749-2761

Stelle LL, Blake RW, Trites AW (2000) Hydrodynamic drag in Steller sea lions (Eumetopias jubatus). J Exp Biol 203: 1915-1923

Editorial responsibility: William Sydeman,

Petaluma, California, USA
Thompson D, Fedak MA (2001) How long should a dive last? A simple model of foraging decisions by breathhold divers in a patchy environment. Anim Behav 61: $287-296$

Trenberth KE, Hurrell JW (1994) Decadal atmosphere-ocean variations in the Pacific. Clim Dyn 9:303-319

- Trites AW, Miller AJ, Maschner HDG, Alexander MA and others (2007) Bottom-up forcing and the decline of Steller sea lions (Eumetopias jubatus) in Alaska: assessing the ocean climate hypothesis. Fish Oceanogr 16:46-67

Tynan CT, DeMaster DP (1997) Observations and predication of Arctic climatic change potential effects on marine mammals. Arctic 50:308-322

Vogel S (1994) Life in moving fluids: the physical biology of flow, 2nd edn. Princeton University Press, Princeton, NJ

- Williams TM (1999) The evolution of cost efficient swimming in marine mammals: limits to energetic optimization. Philos Trans R Soc Lond B Biol Sci 354:193-201

Williams TM (2001) Intermittent swimming by mammals: a strategy for increasing energetic efficiency during diving. Am Zool 41:166-176

Williams TM, Kooyman GL (1985) Swimming performance and hydrodynamic characteristics of harbor seals Phoca vitulina. Physiol Zool 58:576-589

Williams TM, Kooyman GL, Croll DA (1991) The effect of submergence on heart rate and oxygen consumption of swimming seals and sea lions. J Comp Physiol B Biochem Syst Environ Physiol 160:637-644

> Williams TM, Fuiman LA, Horning M, Davis RW (2004) The cost of foraging by a marine predator, the Weddell seal Leptonychotes weddellii: pricing by the stroke. J Exp Biol 207:973-982

Wilson R, White C, Quintana F, Halsey L, Liebsch N, Martin G, Butler PJ (2006) Moving towards acceleration for estimates of activity-specific metabolic rate in free-living animals: the case of the cormorant. J Anim Ecol 75:1081-1090

Wilson RP, Shepard ELC, Liebsch N (2008) Prying into the intimate details of animal lives: use of daily diary tags on animals. Endang Species Res 4:123-137

> Yoda K, Sato K, Niizuma Y, Kurita M, Bost CA, Le Maho Y, Natio Y (1999) Precise monitoring of porpoising behaviour of Adélie penguins determined using acceleration data loggers. J Exp Biol 202:3121-3126

Submitted: August 10, 2009; Accepted: July 29, 2010

Proofs received from author(s): August 13, 2010 